\title{
A INFLUÊNCIA DOS CRITÉRIOS LÓGICOS E FORMAIS DA CAPES NA DISCIPLINARIZAÇÃO DA PRODUÇÃO INTELECTUAL NO CAMPO DAS ARTES/MÚSICA
}

\author{
LA INFLUENCIA DE LA CAPES CRITERIOS \\ LÓGICOS Y FORMALES DISCIPLINAR DE LA \\ PRODUCCIÓN INTELECTUAL EN EL CAMPO DE \\ LAS ARTES / MÚSICA.
}

\author{
Anderson Café* \\ Núbia Moura Ribeiro** \\ Roberto Leon Ponczek***
}

\begin{abstract}
RESUMO
Introdução: Discute-se como o conhecimento mediato, lógico e formal da CAPES, representado pelos seus critérios de avaliação, tem corroborado para a padronização da produção intelectual no campo das Artes, no qual, conforme Hessen (2000), predomina um tipo de conhecimento imediato, informal e intuitivo.
\end{abstract}

Objetivo: Refletir a referida questão, buscando-se evidenciar o grau de padronização e sistematização da produção intelectual em três programas de Pós-graduação pertencentes ao campo das Artes/Música, avaliados pela Capes, em 2013.

Metodologia: Realizou-se uma análise comparativa entre os pesos atribuídos à produção artística e científica no campo das Artes/Música e a efetiva produção dos três programas estudados, publicada entre 2010 e 2012.

Resultados: A análise dos dados revelou que mesmo no campo das Artes/Música, os programas de Pós-graduação ainda são mais pontuados, levando-se em conta a quantidade de artigos científicos publicados que é o *Doutorando em Difusão do Conhecimento pela Universidade Federal da Bahia (UFBA). Servidor do Tribunal de Justiça do Estado da Bahia. E-mail: anderson.cafe@bol.com.br

${ }^{*}$ Doutora em Química pela Universidade Federal do Rio de Janeiro (UFRJ). Docente Permanente do Programa de Pós-Graduação em Difusão do Conhecimento (UFBA). Docente do Instituto Federal de Educação, Ciência e Tecnologia da Bahia (IFBA). Email: nubiamouraribeiro@gmail.com

***Doutor em Educação pela Universidade Federal da Bahia (UFBA). Docente Permanente do Programa de Pós-Graduação em Difusão do Conhecimento (UFBA). Email: ponczek@gmail.com

Inf. Inf., Londrina, v. 21, n. 1, p. 159 - 184, jan./abr. 2016. 
instrumento privilegiado do conhecimento mediato, lógico e formal, em detrimento das produções artísticas, próprias do conhecimento imediato, intuitivo e criativo.

Conclusão: O funcionamento da Pós-graduação está alicerçado em um conjunto de conhecimentos formais, expressos em documentos normativos, através dos quais a CAPES exerce o poder, a disciplina e o estímulo para tornar padronizadas as produções intelectuais.

Palavras-chave: Teoria do conhecimento. Poder disciplinar. Campo científico. Produção intelectual. Sistema de avaliação. CAPES.

\section{INTRODUÇÃO}

Pensar a própria história da existência humana tem suscitado grandes discussões teóricas e filosóficas que se constituíram no verdadeiro problema central da teoria do conhecimento, ou seja, quem veio primeiro: sujeito ou objeto; matéria ou consciência? (HESSEN, 2000).

No decorrer da história ocidental da teoria geral do conhecimento, diferentes foram as correntes de pensamento que enfatizaram a preponderância da consciência do sujeito no processo de construção do conhecimento, a exemplo do racionalismo, subjetivismo e idealismo. Para essas correntes do pensamento filosófico, não há uma realidade exterior fora da mente do sujeito, visto acreditarem na capacidade cognitiva do sujeito como única possibilidade de apreender a realidade que o cerca (HESSEN, 2000). Entretanto, a cada uma dessas correntes correspondem escolas de oposições correspondentes que apresentam uma interpretação contrária a esse pensamento, a exemplo do empirismo, objetivismo e realismo. Para essas escolas de pensamento, o objeto, isto é, o mundo é independente da mente do sujeito (HESSEN, 2000).

Entre esses dois polos de divergências surgiram escolas de pensamento, quase sempre preconizada pelo filósofo Emmanuel Kant, que tentaram realizar a síntese: o criticismo, que busca superar a 
dualidade entre o dogmatismo e o ceticismo; o intelectualismo, que trabalha na perspectiva de conciliar as dicotomias entre o racionalismo e o empirismo e, por último, a fenomenologia, que tentou sintetizar o idealismo e o realismo (HESSEN, 2000).

Assim, refletir sobre como o homem apreende o conhecimento que está ao seu redor também envolve a reflexão formulada por correntes do pensamento filosófico que igualmente estiveram em lados opostos, como a corrente do conhecimento mediato, lógico e formal e a corrente do conhecimento imediato, intuitivo e informal (HESSEN, 2000).

De acordo com a corrente do conhecimento mediato, lógico e formal, a apreensão do conhecimento pelo homem ocorre por meio de sua capacidade cognitiva que lhe permite refletir, estudar, comparar e apreender um conjunto de informações que the são colocadas à disposição. Por outro lado, a corrente do conhecimento imediato, intuitivo e informal acredita que o conhecimento relevante se efetiva diretamente da criatividade (HESSEN, 2000).

Por conseguinte, ao se refletir sobre a política de avaliação da produção científica no âmbito da pós-graduação brasileira efetivada por um arsenal de normas e procedimentos formais, este artigo questiona como o conhecimento mediato, lógico e formal da CAPES, representado nos critérios objetivos do seu sistema de avaliação, tem corroborado para a padronização e sistematização da produção intelectual, ainda que em campos do saber como o da Arte que, de acordo com Hessen (2000), predomina um tipo de conhecimento imediato, informal e intuitivo, ou seja, artístico, cultural e criativo.

Dessa forma, a principal hipótese deste trabalho foi formulada no sentido de argumentar que, apesar das produções artísticas possuírem os mesmos pesos das publicações científicas, como evidencia o quadro 2, os programas de pós-graduação do campo das Artes ainda pontuam mais, na avaliação gestada pela Capes, pela quantidade de artigos completos publicados em periódicos científicos, sendo este último o instrumento privilegiado do conhecimento lógico e formal.

Inf. Inf., Londrina, v. 21, n. 1, p. 159 - 184, jan./abr. 2016. 
Para atingir o objetivo desta pesquisa são apresentados os conceitos teóricos de conhecimento mediato e imediato. Em seguida, discorre-se sobre o conhecimento lógico e formal do sistema de avaliação da CAPES com base na teoria de Hessen (2000), tentando articular esse conceito às reflexões de poder disciplinar propostas por Foucault (1987) e com as proposições de campo científico e capital científico de autoria de Bourdieu (1983, 2001, 2004). No decorrer da exposição, indicam-se os procedimentos metodológicos utilizados para a execução da pesquisa, bem como apresentam-se e discutem-se os resultados obtidos na pesquisa de campo. Por fim, mostram-se as principais conclusões deste artigo.

\section{UMA BREVE DISCUSSÃO ACERCA DO CONHECIMENTO MEDIATO E IMEDIATO}

A dualidade sujeito-objeto, razão-experiência, representaçãorealidade e ideia-matéria são visões de mundo caracterizadas por pensamentos dicotômicos em relação às formas de apreensão do conhecimento. Essa dicotomia é objeto de grande discussão filosófica que permeou toda a história do pensamento ocidental, envolvendo variados pensadores em todo o mundo (HESSEN, 2000).

A corrente da filosofia que vê o mundo a partir do sujeito, do pensamento, da razão, da representação e da ideia acredita em um universo visto por meio da capacidade racional e intelectual do homem para a compreensão dos fenômenos da natureza. Nessa concepção, o homem é ativo e o mundo, contingente e dual. Por outro lado, o mundo do objeto, da experiência, da realidade e da matéria é aquele visto a partir da natureza. Um mundo sem sujeito nem objetos, mas apenas composto por campos de forças (PONCZEK, 2009).

A dicotomia sobre a concepção de mundo também está refletida sobre as formas pelas quais o homem busca "[...] apreender um objeto" (HESSEN, 2000, p. 97). Nesse sentido, há um posicionamento filosófico

Inf. Inf., Londrina, v. 21, n. 1, p. $159-184$, jan./abr. 2016. 
do conhecimento mediato que reflete o homem "[...] como um ser exclusivamente ou preponderantemente teórico, cuja função é pensar e reconhecer apenas o conhecimento racional como válido" (HESSEN, 2000, p. 109) e há, por outro lado, um pensamento do conhecimento imediato que acredita que a compreensão da realidade não está "[...] nas forças intelectuais, mas nas emocionais, volitivas" (HESSEN, 2000, p. 110).

O conhecimento mediato é aquele que depende de um meio para se concretizar, sendo efetivado pela consciência cognitiva. Isso significa que o conhecimento do mundo ocorre por meio da capacidade do homem em apreender o objeto ao seu redor.

Ele relaciona seu objeto a outros, compara-o com outros, tira conclusões e assim por diante. É isso que faz o pesquisador nas ciências especializadas quando quer determinar seu objeto sob todos os ângulos. Mas é também isso que faz o metafísico quando quer, por exemplo, apreender a essência da alma. Em ambos os casos, a consciência cognoscente serve-se das mais diversas operações mentais (HESSEN, 2000, p. 97).

Ao se analisar esse tipo de conhecimento, percebe-se que ele esteve presente em toda a concepção epistemológica do século $X X$, tentando explicar como o sujeito apreende a realidade social, desde as ideias formuladas por Karl Popper até o anarquismo epistemológico de Feyerabend (MASSONI, 2005).

Assim, de acordo com o conhecimento formal, a aquisição de conhecimento está relacionada à capacidade do homem em dar significado cognitivo ao conjunto de informações que dão corpo à estrutura de funcionamento da sociedade, seja no campo educacional, científico, econômico, político e social (HESSEN, 2000; MASSONI, 2005).

Entretanto, além do conhecimento mediato, lógico e formal, há o conhecimento imediato, intuitivo e informal que não depende de nenhum meio para ocorrer. Esse tipo de conhecimento quase sempre se efetiva 
por meio da experiência direta do sujeito com o objeto, estando mais relacionado à capacidade perceptiva do indivíduo.

Sua característica consiste em que, nele, o objeto é imediatamente apreendido, como ocorre principalmente na visão. Não há dúvida de que existe esse conhecimento. Tudo que nos é dado na experiência externa ou interna é imediatamente apreendido por nós (HESSEN, 2000, p. 97).

A palavra intuição, de acordo com Hessen (2000), não deve ser vista apenas pelo viés espiritual como comumente é utilizada, mas também pela concepção das leis lógicas do pensamento. Dentro dessa concepção lógica, a intuição está classificada em dois tipos: formal e material.

A intuição formal ocorre quando o homem consegue apreender a relação lógica existente entre conteúdos sensíveis, afirmando, por exemplo, que vermelho e verde são cores diferentes por conta de suas distintas características claramente visíveis através do órgão sensorial da visão (HESSEN, 2000).

Já a intuição material diferencia-se da formal por não estar atrelada unicamente à apreensão da relação existente entre dois objetos, mas sim ao próprio domínio conceitual dessas distinções que está atrelada "[...] na estrutura psíquica do homem" (HESSEN, 2000, p. 98). Uma manifestação da intuição material está relacionada aos sentimentos de um indivíduo quando da apreciação de uma obra de arte. Intuição essa, não perceptível por meio do órgão sensorial da visão.

No decorrer da história, o problema da intuição foi discutido por grandes pensadores da filosofia como Platão, Agostinho, Tomás de Aquino, Descartes, Espinosa, Leibniz, Kant, David Hume, Fries, Schleiermacher, Bergson, dentre outros. Cada um desses pensadores mostrou o seu ponto de vista em relação à influência desse tipo de conhecimento na compreensão do mundo (HESSEN, 2000). 
A intuição também foi analisada em diferentes perspectivas teóricas. No que tange a filosofia contemporânea, a intuição ainda é vista com muitas reservas. Situação semelhante ocorre no campo do realismo crítico, no qual esse tipo de conhecimento é "[...] predominantemente negativo" (HESSEN, 2000, p. 105). No campo da metafísica, por sua vez, a intuição é aceita pelos teóricos sem grandes restrições. Por fim, percebe-se, nas discussões propostas por Hessen (2000), que nos campos das artes, dos valores, da estética, da ética, e da religião, a intuição não gera muita polêmica, pois há um maior grau de aceitação desse tipo de conhecimento como possibilidade de construção de novos saberes.

Como principal avaliadora do conjunto de conhecimentos produzido no âmbito das 48 áreas de avaliação, a próxima seção deste artigo trata, dentre outras questões, sobre os critérios lógicos e formais utilizados pela CAPES para disciplinar a produção intelectual produzida no seio dos programas de pós-graduação, inclusive em campos do saber no qual o conhecimento intuitivo e criativo obtêm um maior grau de aceitação.

\section{OS DISPOSITIVOS DISCIPLINARES DA CAPES NA PÓS- GRADUAÇÃO BRASILEIRA}

Após a breve discussão sobre os conhecimentos mediatos e imediatos que possibilitam ao homem apreender a realidade ao seu redor, fez-se necessário refletir sobre os critérios de avaliação da CAPES que, no entendimento deste artigo, é do tipo lógico e formal e que tem corroborado para controlar e padronizar a produção científica nos cursos de pós-graduação.

A CAPES é uma agência de fomento à pesquisa, atualmente vinculada ao Ministério da Educação. Criada pelo decreto ํo 29.741, de 11 de julho de 1951, no governo de Getúlio Dornelles Vargas (19511954), o objetivo principal da CAPES é qualificar pessoal especializado

Inf. Inf., Londrina, v. 21, n. 1, p. 159 - 184, jan./abr. 2016. 
para atender às demandas dos empreendimentos públicos e privados no país. Entretanto, para atender à referida demanda, a CAPES estimulou a crescente expansão de programas de pós-graduação em todo o território brasileiro, esse crescimento demandou a formulação de uma sistemática de avaliação pautada em critérios lógicos, formais e objetivos a fim de garantir, de acordo com o discurso lógico da CAPES, a qualidade das atividades desempenhadas pelos docentes e discentes neles inseridos.

A partir de 2013, a CAPES alterou a sua escala temporal de avaliação, passando a examinar os programas de pós-graduação, das 48 áreas do conhecimento, de quatro em quatro anos. Nesta avaliação, a referida agência utiliza-se de escalas de mensuração que variam de 1 (um) a 7 (sete), em substituição ao sistema anterior de avaliação, vigente até o ano de 1996, aos quais se atribuíam conceitos A, B, C, D e E. Os programas de mestrados detentores de notas 1 ou 2, em avaliações quadrienais, são descredenciados e não podem ofertar novas turmas. O mesmo ocorre com os programas de doutorado, já que aqueles que obtiverem conceitos 1,2 ou 3, durante um quadriênio, também têm suas atividades encerradas (CAPES, 2013a).

Nesse sentido, a CAPES tem exercido um significativo poder disciplinar (FOUCAULT, 1987) em relação aos programas de pósgraduação no Brasil, na medida em que avalia, a cada quadriênio, as atividades desempenhadas pelos mesmos, punindo-os com a diminuição de conceitos e, consequentemente, de recursos financeiros, caso os mesmos não sigam os critérios lógicos e formais da agência ou premiando-os com o aumento de conceitos e capitais financeiros para custeio das atividades caso se enquadrem satisfatoriamente aos critérios estabelecidos.

Cada Comitê Técnico-Científico de campo do conhecimento que atua na CAPES é responsável pela elaboração de seu documento de área que contém, dentre outras informações, as métricas utilizadas para avaliar os programas de pós-graduação. Essas métricas envolvem a 
avaliação de cinco quesitos: proposta do programa (que não possui uma pontuação específica, mas cuja avaliação é transversal aos demais quesitos); produção intelectual; corpo discente, teses e dissertações; corpo docente e inserção social, os quais, somados aos seus respectivos pesos, fundamentam o quesito relativo à proposta dos programas (CAPES, 2013a). O quadro 1 mostra o peso/ percentual dado aos quesitos de avaliação para as áreas das Artes/Música.

Quadro 1 - Síntese dos pesos dos quesitos da avaliação das áreas das Artes/Música (2013)

\begin{tabular}{|l|c|}
\hline \multicolumn{1}{|c|}{ Quesitos de avaliação } & $\%$ \\
\hline Produção Intelectual. & 35 \\
\hline Corpo Discente, teses e dissertações. & 35 \\
\hline Corpo Docente. & 20 \\
\hline Inserção Social. & 10 \\
\hline
\end{tabular}

Fonte: CAPES (2013a).

O quesito produção intelectual corresponde aos produtos científicos dos docentes dos programas de pós-graduação publicados em livros, capítulos de livros, artigos de periódicos científicos e comunicação em anais de eventos científicos, e representam 35\% do conjunto da avaliação realizada pela CAPES para a área utilizada aqui como exemplo: Artes/Música. No quadro 2, pode-se conhecer os itens utilizados pela CAPES para avaliar o quesito produção intelectual para as áreas das Artes/Música (CAPES, 2013a).

Quadro 2 - Itens da avaliação da produção intelectual nas áreas das Artes/Música (2013)

\begin{tabular}{|l|c|}
\hline \multicolumn{1}{|c|}{ Itens de avaliação } & Peso \\
\hline Publicações qualificadas do programa por docente permanente. & 30,0 \\
\hline $\begin{array}{l}\text { Distribuição de publicações qualificadas em relação ao corpo } \\
\text { docente permanente do programa. }\end{array}$ & 30,0 \\
\hline $\begin{array}{l}\text { Produção técnica, patentes e outras produções consideradas } \\
\text { relevantes. }\end{array}$ & 10,0 \\
\hline $\begin{array}{l}\text { Produção artística, nas áreas em que tal tipo de produção for } \\
\text { pertinente. }\end{array}$ & 30,0 \\
\hline
\end{tabular}

Fonte: CAPES (2013a).

Inf. Inf., Londrina, v. 21, n. 1, p. 159 - 184, jan./abr. 2016. 
Consequentemente, o quesito relacionado ao corpo discente, teses e dissertações afere, dentre outros elementos, a quantidade de teses e dissertações defendidas e publicadas em livros, capítulos de livros, artigo de periódicos e anais de eventos científicos no período de até três anos após as defesas. Esse quesito, cujos itens de avaliação estão descritos no quadro 3, representa $35 \%$ do conjunto da avaliação dos programas de pós-graduação para as áreas das Artes/Música (CAPES, 2013a).

Quadro 3 - Itens da avaliação do corpo discente, teses e dissertações nas Artes/Música (2013)

\begin{tabular}{|l|c|}
\hline \multicolumn{1}{|c|}{ Itens de avaliação } & Peso \\
\hline $\begin{array}{l}\text { Quantidade de teses e dissertações defendidas no período de } \\
\text { avaliação, em relação ao corpo docente permanente e à } \\
\text { dimensão do corpo discente. }\end{array}$ & 40,0 \\
\hline $\begin{array}{l}\text { Distribuição das orientações das teses e dissertaçães defendidas } \\
\text { no período de avaliação em relação aos docentes do programa. }\end{array}$ & 20,0 \\
\hline $\begin{array}{l}\text { Qualidade das teses e dissertações e da produção de discentes } \\
\text { autores da pós-graduação e da graduação (no caso de IES com } \\
\text { curso de graduação) na produção científica do programa, aferida } \\
\text { por publicações e participação na produção técnica e artística do } \\
\text { programa. }\end{array}$ & 50,0 \\
\hline $\begin{array}{l}\text { Eficiência do programa na formação de mestres e doutores } \\
\text { bolsistas: tempo de formação de mestres e doutores e percentual } \\
\text { de bolsistas titulados. }\end{array}$ & 15,0 \\
\hline
\end{tabular}

Fonte: CAPES (2013a).

Em relação ao quesito corpo docente, a CAPES avalia o perfil acadêmico dos docentes do programa, a dedicação deles em relação às atividades de pesquisas, a distribuição dessas atividades e a contribuição dos docentes para atividades de ensino e pesquisa. $O$ referido quesito representa $20 \%$ do conjunto da avaliação para as áreas das Artes/Música, estando os itens relacionados no quadro 4 (CAPES, 2013a). 
Quadro 4 - Itens da avaliação do corpo docente nas áreas das Artes/Músicas (2013)

\begin{tabular}{|l|c|}
\hline \multicolumn{1}{|c|}{ Itens de avaliação } & Peso \\
\hline $\begin{array}{l}\text { Perfil do corpo docente, consideradas titulação, diversificação } \\
\text { na origem de formação, aprimoramento e experiência, e sua } \\
\text { compatibilidade e adequação à proposta do programa. }\end{array}$ & 30,0 \\
\hline $\begin{array}{l}\text { Adequação e dedicação dos docentes permanentes em relação } \\
\text { às atividades de pesquisa e de formação do programa. }\end{array}$ & 30,0 \\
\hline $\begin{array}{l}\text { Distribuição das atividades de pesquisa e de formação entre os } \\
\text { docentes do programa. }\end{array}$ & 30,0 \\
\hline $\begin{array}{l}\text { Contribuição dos docentes para atividades de ensino e/ou de } \\
\text { pesquisa na graduação, com atenção tanto à repercussão que } \\
\text { este item pode ter na formação de futuros integrantes na PG, } \\
\text { quanto na formação de profissionais mais capacitados no plano } \\
\text { da graduação. }\end{array}$ & 10,0 \\
\hline
\end{tabular}

Fonte: CAPES (2013a).

Por último, o quesito inserção social, ora inserido na avaliação dos programas de pós-graduação no governo do então presidente Luiz Inácio Lula da Silva, mensura o impacto regional e nacional do programa de pós-graduação, a integração e cooperação com outros programas e a visibilidade ou transparência dado pelo programa às suas ações. Esse quesito corresponde $10 \%$ do conjunto total da avaliação para as áreas das Artes/Música, cujos pesos e itens de avaliação estão descritos no Quadro 5 (CAPES, 2013a).

Quadro 5 - Itens da avaliação da inserção social nas áreas das Artes/Música (2013)

\begin{tabular}{|l|c|}
\hline \multicolumn{1}{|c|}{ Itens de avaliação } & Peso \\
\hline Inserção e impacto regional e (ou) nacional do programa. & 40,0 \\
\hline $\begin{array}{l}\text { Integração e cooperação com outros programas e centros de } \\
\text { pesquisa e desenvolvimento profissionais relacionados à área } \\
\text { de conhecimento do programa, com vistas ao desenvolvimento } \\
\text { da pesquisa e da pós-graduação. }\end{array}$ & 40,0 \\
\hline $\begin{array}{l}\text { Visibilidade ou transparência dada pelo programa à sua } \\
\text { atuação. }\end{array}$ & 20,0 \\
\hline
\end{tabular}

Fonte: CAPES (2013a).

Inf. Inf., Londrina, v. 21, n. 1, p. 159 - 184, jan./abr. 2016. 
Como se observa, são esses os dispositivos utilizados pela CAPES para disciplinar os corpos daqueles que estão inseridos dentro dos programas de pós-graduação brasileiros, sendo que, para Foucault (1987), toda disciplina exercida nos múltiplos espaços sociais como escola, família, presídios, manicômios e, porque não, em programas de pós-graduação, tem como objetivo produzir corpo dócil que possa ser "[...] submetido, utilizado, transformado e aperfeiçoado" (FOUCAULT, 1987, p. 118).

A produção de corpos dóceis, na perspectiva Foucaultiana, está relacionada à desarticulação política dos indivíduos dentro dos espaços sociais e sua maximização em termos produtivos, sendo que no campo da pós-graduação brasileira essa produtividade é mensurada, como se percebe nos critérios mostrados anteriormente, pela quantidade $\mathrm{e}$ qualidade da produção científica dos docentes e discentes que, como se discutiu, representa cerca de $70 \%$ (resultante da soma dos quesitos produção intelectual e corpo discente, teses e dissertações) dentre os outros quesitos de avaliação observável.

Dentro dessa lógica de socialização dos corpos que fabrica sujeitos disciplinados e produtivos no interior dos variados espaços sociais, Bourdieu $(1983,2001,2004)$ lembra que no campo científico a produtividade dos agentes é medida pela sua capacidade de reproduzir, de forma mais eficiente possível, por meio do que o teórico chama de habitus, as regras de funcionamento do campo científico, sendo o resultado dessa reprodução medida pela quantidade de capital científico acumulado.

Para Bourdieu (2001), todas as disputas dentro do campo científico estão orientadas para o acúmulo de capital científico. Pois, ao acumular capital científico, o agente faz seu nome, isto é, busca ser conhecido e reconhecido entre os seus pares-concorrentes pela quantidade e qualidade da produção científica ou pela ocupação de posições políticas importantes dentro do campo (BOURDIEU, 1983).

Existem duas espécies de representação do capital científico: o 
capital científico puro e o capital científico temporal. O puro está relacionado ao prestígio individual do pesquisador, ou seja, ao reconhecimento de sua habilidade intelectual que "[...] repousa quase sempre exclusivamente sobre o reconhecimento, pouco ou mal objetivado e institucionalizado, do conjunto de pares ou da fração mais consagrada dentre eles” (BOURDIEU, 2004, p. 35). Por sua vez, o temporal é o acumulado pelos agentes por meio de estratégias políticas e está quase sempre relacionado "[...] à ocupação de posições importantes nas instituições científicas, direção de laboratório ou departamentos, pertencimento a comissões, comitês de avaliação, etc." (BOURDIEU, 2004, p. 35).

Dessa maneira, esta seção do artigo mostra que os dispositivos lógicos e formais utilizados pela CAPES ainda estão fortemente estruturados para avaliar o capital científico puro dos programas de pósgraduação, isto é, aquele mensurável pela produção científica, sendo que o capital científico temporal pode ser entendido como aquele resultante do próprio processo avaliativo da CAPES que atribui um conceito aos programas avaliados e que, na ótica de Bourdieu (1983, 2001, 2004), representa um capital simbólico que afere aos mesmos prestígios, reconhecimento e autoridade científica dentro do campo da pós-graduação.

Nesse sentido, a permanente busca de acumulação de capital científico dentro do campo da pós-graduação brasileira, medida, quase sempre, pela produção intelectual, aliada ao forte exercício do poder disciplinar exercido pela CAPES, sobretudo no que diz respeito ao aumento da produção científica, tem corroborado para o surgimento de uma lógica produtivista refletida na crescente falta de qualidade e até da lisura de muitas publicações científicas. Dessa forma, esse tema tem sido objeto de calorosas discussões entre muitos intelectuais brasileiros como Santos (2003); Arx (2004); Luz (2005); Carvalho e Manoel (2006); Luiz (2006); Oliveira (2008); Rosa (2008); Arruda (2010); Correia, Alvarenga e Garcia (2011) e Ponczek (2013). 


\section{METODOLOGIA}

Com o objetivo de analisar, ainda que de forma breve, sobre como o conhecimento mediato, lógico e formal presente no sistema de avaliação da CAPES tem contribuído para o processo de disciplinarização da produção intelectual mesmo dentro de programas de pós-graduação pertencentes a campos do conhecimento típico de uma produção artística, cultural e criativa, buscou-se selecionar, entre as 48 áreas de avaliação da CAPES, aquela área que estivesse mais próxima de representar essa produção artística e criativa, escolhendo-se as áreas das Artes/Música.

Escolhida a área das Artes/Música que, conforme Hessen (2000) possui um maior grau de aceitação do tipo de conhecimento imediato, intuitivo e informal, representado pelo saber artístico e criativo, pesquisou-se o documento de área e o relatório de avaliação das Artes/Música para obtenção dos critérios de avaliação da produção intelectual e os pesos atribuídos à produção artística e científica.

Após pesquisa documental, no portal eletrônico da CAPES, efetivou-se a escolha de 3 (três) programas que compuseram a amostra desta pesquisa, utilizando-se da técnica da amostragem aleatória simples, onde os 50 programas que constituíram a população possuíram a mesma probabilidade de serem escolhidos. O método para obtenção da amostra foi o sorteio, no qual se escolheu programa por programa até que fosse completada a amostra. Os programas sorteados foram: Teatro, mantido pela Universidade Estadual de Santa Catarina (UDESC); Artes Cênicas, de responsabilidade da Universidade Federal do Rio Grande do Norte (UFRN) e Artes Cênicas, vinculado à Universidade de São Paulo (USP). 
Anderson Café; Núbia Moura Ribeiro; Roberto Leon Ponczek

A influência dos critérios lógicos e formais da CAPES na disciplinarização da produção intelectual no campo das artes/música

Quadro 6 - Quadro síntese das características dos programas sorteados

\begin{tabular}{|c|c|c|c|c|}
\hline Curso & IES & Região geográfica & Nível & Conceito \\
\hline Teatro & UDESC & Sul & $\begin{array}{l}\text { Mestrado / } \\
\text { Doutorado }\end{array}$ & 5 \\
\hline $\begin{array}{c}\text { Artes } \\
\text { Cênicas }\end{array}$ & UFRN & Nordeste & Mestrado & 3 \\
\hline $\begin{array}{c}\text { Artes } \\
\text { Cênicas }\end{array}$ & USP & Sudeste & $\begin{array}{l}\text { Mestrado / } \\
\text { Doutorado }\end{array}$ & 6 \\
\hline
\end{tabular}

Fonte: CAPES (2013b).

Como é possível observar no quadro 6 a amostra selecionada para esta pesquisa é composta por programas de pós-graduação localizados em pelo menos três das cinco regiões geográficas do país, possuindo programas detentores de cursos em nível de treinamento de mestrado e doutorado possuidores de diferentes conceitos atribuídos pela CAPES em seu sistema avaliativo. Dessa forma, acredita-se que os resultados desta amostra podem ser considerados representativos da própria área de conhecimento e contribuem para o entendimento sobre a influência dos critérios lógicos e formais da CAPES na produção intelectual dos programas de pós-graduação no campo das Artes/Música.

Sorteados os programas, realizou-se pesquisa documental nos cadernos de indicadores de cada um deles, buscando-se efetivar uma comparação entre a produção registrada no caderno produção artística e aquela constante no caderno de produção bibliográfica publicado entre 2010 e 2012.

Os dados coletados foram registrados, inicialmente, em tabelas elaboradas no Microsoft Excel versão 2010 e, posteriormente, serviram de base para a composição dos quadros apresentados na seção dos resultados. Por último, os dados foram analisados à luz da literatura que sustentou esta comunicação do ponto de vista teórico e epistemológico.

As considerações finais desta pesquisa serão apresentadas na última seção deste artigo.

Inf. Inf., Londrina, v. 21, n. 1, p. $159-184$, jan./abr. 2016. 


\section{RESULTADOS E DISCUSSÕES}

O campo da pós-graduação em Artes/Música possui, atualmente, 50 programas, sendo 22 mestrados acadêmicos; 4 mestrados profissionais e 24 programas que possuem tanto mestrado quanto doutorado. O primeiro programa de pós-graduação sorteado para compor a amostra desta pesquisa foi o programa de Teatro que é mantido pela UDESC e cujo conceito obtido na trienal 2013 foi 5. Durante a avaliação trienal, o programa contou com 14 docentes, sendo que 11 deles atuaram como permanente nos três anos da avaliação, 2 atuaram como permanente somente no ano de 2012 e 1 atuou também como colaborador nos três anos avaliados pela CAPES.

O quadro 7 revela que o Programa de Teatro da UDESC produziu 93 artes cênicas, sendo 25 em 2010, 35 em 2011 e 33 em 2012, assim como publicou 92 artigos de periódicos científicos, sendo 28 em 2010, 36 em 2011 e 28 em 2012. Como é possível verificar, existe certo equilíbrio entre o número total de artes cênicas produzidas no período e o quantitativo de artigos de periódicos científicos publicado pelo programa.

Entretanto, ao se observar a produção publicada nos estratos superiores do campo das Artes/ Música, ou seja, a produção publicada em estratos $A 1$ e $A 2$, os dados revelaram que foram produzidas 17 artes cênicas nesses estratos e quase 0 dobro dessa produção em artigos de periódicos científicos: 32 artigos em ambos os estratos. 
Quadro 7 - Produção artística e bibliográfica do programa de Teatro da UDESC

\begin{tabular}{|c|c|c|c|c|c|c|c|c|c|}
\hline \multicolumn{4}{|c|}{ Artes cênicas } & \multicolumn{4}{c|}{ Artigo de periódico científico } \\
\hline Estrato & Peso & 2010 & 2011 & 2012 & Estrato & Peso & 2010 & 2011 & 2012 \\
\hline A1 & 100 & 1 & 1 & 3 & A1 & 100 & 11 & 8 & 9 \\
\hline A2 & 85 & 0 & 5 & 7 & A2 & 85 & 1 & 3 & 0 \\
\hline B1 & 70 & 17 & 7 & 5 & B1 & 70 & 1 & 0 & 2 \\
\hline B2 & 60 & 1 & 1 & 4 & B2 & 60 & 3 & 1 & 2 \\
\hline B3 & 40 & 1 & 8 & 5 & B3 & 40 & 6 & 2 & 4 \\
\hline B4 & 20 & 5 & 12 & 7 & B4 & 30 & 2 & 19 & 6 \\
\hline B5 & 5 & 0 & 1 & 2 & B5 & 10 & 2 & 2 & 3 \\
\hline C & 0 & 0 & 0 & 0 & C & 0 & 2 & 1 & 2 \\
\hline SUBTOTAL & 1.490 & 1.640 & 1.835 & SUBTOTAL & 1.755 & 1.785 & 1.530 \\
\hline \multicolumn{3}{|c|}{ TOTAL } & \multicolumn{3}{|c|}{4.965} & \multicolumn{5}{c|}{ TOTAL } & & $\mathbf{5 . 0 7 0}$ \\
\hline
\end{tabular}

Fonte: Pesquisa elaborada pelos autores no caderno de indicadores da CAPES.

Ao analisar o quadro 7 , verifica-se, dentre outras coisas, que durante 0 triênio, o programa da UDESC produziu apenas 5 artes cênicas no estrato A1 (dotado de maior capital científico dentro desse campo do conhecimento) enquanto produziu 28 artigos nesse mesmo estrato, representando uma diferença significativa entre os dois tipos de produção.

Outra constatação mostrada no quadro 7 é a existência de diferenças entre os pesos atribuídos aos estratos B4 e B5, referentes à produção artística e a produção bibliográfica. Esta diferença de pesos pode ser considerada uma variável importante para explicar as razões pelas quais o programa obteve maior pontuação na produção publicada em artigo de periódico científico em detrimento das artes cênicas.

Enquanto o programa publicou 24 artes cênicas no estrato B4 e 3 no estrato B5, que possuem pesos respectivos de 20 e 5, o programa produziu 27 artigos no estrato B4 e 7 no $B 5$, que possuem pesos 30 e 10 respectivamente, contribuindo, fortemente, para o programa obter 
4.965 pontos em artes cênicas e 5.070 em artigo de periódico científico.

Por sua vez, o segundo programa sorteado para compor a amostra desta investigação foi o programa de Artes Cênicas da UFRN que obteve conceito 3 na última avaliação trienal realizada pela CAPES, em 2013. O programa contou com 15 docentes, dos quais 14 atuaram como permanentes e 1 como colaborador nos três anos avaliados.

O programa, conforme mostra o quadro 8 , produziu um total de 53 artes cênicas, sendo 27 em 2010, 15 em 2011 e 11 em 2012, bem como publicou também um total de 25 artigos de periódicos científicos, sendo 8 em 2010, 8 em 2011 e 9 em 2012. Diferentemente do equilíbrio quantitativo entre produção artística e artigo de periódico científico encontrado na produção do programa da UDESC, os pesquisadores da UFRN produziram mais que o dobro de artes cênicas quando comparado ao total de artigos de periódicos científicos.

Apesar dessa diferença quantitativa, os dados exibidos no quadro 8 mostraram que, assim como ocorreu com o programa de Teatro da UDESC, o programa de Artes Cênicas da UFRN também alcançou maior pontuação na produção publicada em artigos de periódicos científicos do que em produtos de artes cênicas.

Quadro 8 - Produção artística e bibliográfica do programa de Artes Cênicas da UFRN

\begin{tabular}{|c|c|c|c|c|c|c|c|c|c|}
\hline \multicolumn{5}{|c|}{ Artes cênicas } & \multicolumn{5}{|c|}{ Artigo de periódico científico } \\
\hline Estrato & Peso & 2010 & 2011 & 2012 & Estrato & Peso & 2010 & 2011 & 2012 \\
\hline A1 & 100 & 1 & 0 & 0 & A1 & 100 & 1 & 2 & 0 \\
\hline $\mathrm{A} 2$ & 85 & 0 & 1 & 0 & A2 & 85 & 1 & 2 & 0 \\
\hline B1 & 70 & 0 & 1 & 0 & B1 & 70 & 1 & 0 & 2 \\
\hline B2 & 60 & 0 & 0 & 0 & B2 & 60 & 1 & 2 & 0 \\
\hline B3 & 40 & 2 & 0 & 0 & B3 & 40 & 0 & 0 & 1 \\
\hline B4 & 20 & 11 & 9 & 10 & B4 & 30 & 0 & 1 & 1 \\
\hline B5 & 5 & 13 & 3 & 1 & B5 & 10 & 3 & 1 & 4 \\
\hline C & 0 & 0 & 1 & 0 & C & 0 & 1 & 0 & 1 \\
\hline \multicolumn{2}{|c|}{ SUBTOTAL } & 465 & 350 & 205 & \multicolumn{2}{|c|}{ SUBTOTAL } & 345 & 530 & 250 \\
\hline \multicolumn{2}{|c|}{ TOTAL } & \multicolumn{3}{|c|}{1.020} & \multicolumn{2}{|c|}{ TOTAL } & \multicolumn{3}{|c|}{1.125} \\
\hline
\end{tabular}

Fonte: Pesquisa elaborada pelos autores no caderno de indicadores da CAPES.

Inf. Inf., Londrina, v. 21, n. 1, p. $159-184$, jan./abr. 2016. 
O quadro 8 indica, inclusive, que a produção em artigo de periódico científico nos estratos $\mathrm{A} 1$ e $\mathrm{A} 2$ é três vezes superiores à produção de artes cênicas, corroborando, de certa forma, para explicar os motivos pelos quais apesar da menor quantidade de artigos publicados no período investigado, o programa ainda pontua mais por meio da publicação típica do conhecimento lógico e formal da ciência.

Complementando as discussões traçadas acima, os dados salientaram, ainda, que 47 das 53 artes cênicas produzidas pelo programa da UFRN, isso é, (89\%) delas foram publicadas nos estratos B4 e B5 que correspondem às produções artísticas "apresentadas ao público em eventos de abrangência local" (CAPES, 2013a, p. 15). Já em relação à produção de artigos de periódicos científicos, os dados revelaram que 10 dos 25 artigos, ou seja, (40\%) do total foram publicados nessas mesmas classes, no mesmo espaço temporal, revelando, portanto, que os docentes deste programa estão comunicando as suas produções em espaços de pouca visibilidade internacional, o que pode, inclusive, estar comprometendo a própria avaliação do programa que, na última avaliação trienal, obteve conceito 3.

O terceiro programa de pós-graduação sorteado foi o programa de Artes Cênicas da USP que obteve conceito 6 na trienal 2013. O programa contou com um total de 25 docentes, sendo que 20 deles atuaram como permanentes em todos os três anos de avaliação, 1 atuou como colaborador em 2010 e 2011, 2 atuaram como visitantes em 2012 e 2 atuaram como permanentes em 2011 e 2012.

O quadro 9 indica que os docentes do programa de Artes Cênicas da USP produziram um total de 107 artes, sendo 26 em 2010, 52 em 2011 e 29 em 2012, bem como 144 artigos de periódicos, dos quais 24 foram publicados em 2010, 57 em 2011 e 63 em 2012. Assim como foi revelado nos dados anteriores, o quadro 9 mostra que a produção publicada nos estratos possuidores de maior capital científico acumulado, isto é, nos estratos A1 e A2 está concentrada em artigos de 
periódicos, representando um pouco mais que o dobro da produção artística publicada nesses mesmos estratos em igual espaço temporal.

Quadro 9 - Produção artística e bibliográfica do programa de Artes Cênicas da USP

\begin{tabular}{|c|c|c|c|c|c|c|c|c|c|}
\hline \multicolumn{5}{|c|}{ Artes cênicas } & \multicolumn{5}{|c|}{ Artigo de periódico científico } \\
\hline Estrato & Peso & 2010 & 2011 & 2012 & Estrato & Peso & 2010 & 2011 & 2012 \\
\hline $\mathrm{A} 1$ & 100 & 0 & 5 & 5 & A1 & 100 & 8 & 9 & 20 \\
\hline $\mathrm{A} 2$ & 85 & 1 & 1 & 3 & A2 & 85 & 0 & 3 & 1 \\
\hline B1 & 70 & 2 & 11 & 1 & B1 & 70 & 0 & 0 & 0 \\
\hline B2 & 60 & 0 & 4 & 5 & B2 & 60 & 1 & 2 & 3 \\
\hline B3 & 40 & 0 & 7 & 4 & B3 & 40 & 5 & 2 & 8 \\
\hline B4 & 20 & 21 & 18 & 9 & B4 & 30 & 0 & 2 & 0 \\
\hline B5 & 5 & 2 & 5 & 2 & B5 & 10 & 2 & 2 & 4 \\
\hline$C$ & 0 & 0 & 1 & 0 & $C$ & 0 & 8 & 37 & 27 \\
\hline \multicolumn{2}{|c|}{ SUBTOTAL } & 655 & 2.260 & 1.475 & \multicolumn{2}{|c|}{ SUBTOTAL } & 1.080 & 1.435 & 2.625 \\
\hline \multicolumn{2}{|c|}{ TOTAL } & \multicolumn{3}{|c|}{4.390} & \multicolumn{2}{|c|}{ TOTAL } & \multicolumn{3}{|c|}{5.140} \\
\hline
\end{tabular}

Fonte: Pesquisa elaborada pelos autores no caderno de indicadores da CAPES.

Os dados revelaram, ainda, que a produção artística da USP está concentrada no estrato $\mathrm{B} 4$, acumulando 48 produções e representando (45\%) de toda a produção artística do programa, mostrando que mesmo dentro de um programa conceito 6 , a produção artística ocorre predominantemente em espaços de pouca visibilidade internacional enquanto que a produção de artigos de periódicos científico é muito forte nos estratos $A$, cujos títulos são avaliados, dentre outros quesitos, pelo grau de internacionalização das pesquisas publicadas neles, visto que são classificados de acordo com a quantidade de "[...] autores e coautores de instituições estrangeiras reconhecidas". (CAPES, 2013a, p. 12).

Dessa maneira, os dados revelaram, de modo geral, que, apesar dos pontos de resistências discutidos por Foucault (1987) ao exercício do poder disciplinar nos campos científicos (BOURDIEU, 1983, 2001, 
2004) que, no caso da pós-graduação brasileira, teve como uma de suas manifestações às lutas encampadas por intelectuais, os quais reivindicaram, dentre outras questões, à criação do Qualis artístico próprio para avaliar a produção artística (ROSA, 2008; ARRUDA, 2010; CORREIA; ALVARENGA; GARCIA, 2011), os resultados aqui apresentados indicam que os programas do campo das Artes/Música ainda recebem maior pontuação da CAPES pela produção de artigo de periódico científico e não, como era de se esperar, pela produção artística. Dessa forma, os resultados permitiram constatar, dentre outras coisas, que existe um forte exercício do poder disciplinar no âmbito da CAPES, no sentido de padronizar e sistematizar a produção intelectual dentro dos programas de pós-graduação, ainda que em campos típicos de um saber artístico, criativo e intuitivo.

\section{CONCLUSÃO}

Esta comunicação teve como principal objetivo contribuir para a discussão sobre como o conhecimento do tipo lógico, formal e discursivo, presente em documentos normativos da CAPES, tem corroborado para a padronização e sistematização da produção intelectual nos programas de pós-graduação, inclusive, em campos do conhecimento marcado historicamente pela maior produção de um tipo de conhecimento informal, intuitivo e criativo, como é o caso do campo das Artes/Música.

Dessa forma, os resultados desta pesquisa permitiram confirmar a única e principal hipótese lançada para este estudo, mostrando que, mesmo no campo das Artes/Músicas, onde se pressupunha, conforme Hessen (2000), maior produção artística em detrimento da científica, os dados revelaram que os programas de pós-graduação das Artes/Música ainda recebem maior pontuação pela produção científica publicada em artigos de periódicos científicos.

Nesse sentido, os dados da pesquisa possibilitam inferir, de certo

Inf. Inf., Londrina, v. 21, n. 1, p. 159 - 184, jan./abr. 2016. 
modo, que a CAPES, enquanto principal agência de fomento responsável pela atribuição de capital científico aos programas de pósgraduação se utiliza do conhecimento do tipo lógico, formal e discursivo, presentes em documentos de áreas e relatórios de avaliações, para exercer o controle da produtividade acadêmica, favorecendo a produção científica em detrimento da produção artística.

Assim, os resultados desta pesquisa sugerem, de certa forma, que os docentes dos programas de pós-graduação das áreas das Artes/Música estão deixando de produzir suas manifestações artísticas e culturais, próprias desse campo do conhecimento, para elaborarem artigos de periódicos científicos que é um tipo de instrumento privilegiado do conhecimento lógico e formal.

Como foi possível perceber, há uma grande dicotomia entre as manifestações artísticas e culturais e a produção científica nos três programas estudados. Enquanto a produção artística ocorre predominantemente em espaços locais e de pouca visibilidade internacional, a produção de artigo científico é publicada significativamente em títulos de periódicos dotados de maior grau de internacionalização e, consequentemente, de visibilidade científica, na perspectiva do conhecimento lógico e formal da ciência.

Dessa maneira, o forte controle disciplinar exercido pela CAPES no que diz respeito, sobretudo, a produção científica publicada em artigo de periódico, bem como a permanente busca dos pesquisadores pela maior acumulação de capital científico que thes permitam ampliar o reconhecimento acadêmico dentro do campo, tem contribuído para o surgimento de uma lógica pautada, sobretudo, em práticas produtivistas, cuja qualidade e lisura das publicações científicas têm se constituído em objeto de constantes debates na literatura como ocorre nas publicações de Santos (2003); Arx (2004); Luz (2005); Carvalho e Manoel (2006); Luiz (2006); Oliveira (2008); Rosa (2008); Arruda (2010); Correia, Alvarenga e Garcia (2011) e Ponczek (2013).

Este artigo não teve a pretensão de esgotar a discussão sobre o 
sistema de avaliação da CAPES, mas se constitui em um primeiro passo para se pensar esse sistema como uma maquinaria de produção de subjetividades disciplinadas, ou seja, de docentes e discentes que, a cada dia, precisam estar conformados às normas de funcionamento da pós-graduação brasileira como forma de garantir a sua própria sobrevivência dentro desse sistema, comprometendo, inclusive, a criatividade, a intuição e a autonomia desses pesquisadores.

\section{REFERÊNCIAS}

ARRUDA, Cármen Lúcia Rodrigues. Produção artística na universidade: relações de trabalho do professor - artista na Unicamp. Comunicações, Piracicaba, ano 17, n. 2, p. 51-64, jul./dez. 2010.

AXT, Margarete. O pesquisador frente à avaliação na pós-graduação: em pauta novos modos de subjetivação. Psicologia \& Sociedade, Belo Horizonte, v. 16, n. 1, p. 69-85, 2004.

BOURDIEU, Pierre. O campo científico. In: Sociologia. São Paulo: Ática, 1983. p. 122-155.

BOURDIEU, Pierre. Os usos sociais da ciência: por uma sociologia clínica do campo científico. São Paulo: UNESP, 2004.

BOURDIEU, Pierre. Para uma sociologia da ciência. Lisboa: Edições 70, 2001. (Coleção Biblioteca, 70).

CARVALHO, Yara M.; MANOEL, Edison J. Para além dos indicadores de avaliação da produção intelectual na grande área da saúde.

Movimento, Porto Alegre, v. 12, n. 3, p. 193-225, set./dez. 2006.

COORDENAÇÃO DE APERFEIÇOAMENTO DE PESSOAL DE NÍVEL SUPERIOR - CAPES. Avaliação da pós-graduação: documento de área da trienal 2013 - artes/ música). 2013a. Disponível em: <http://www.capes.gov.br>. Acesso em: 17 mar. 2014.

COORDENAÇÃO DE APERFEIÇOAMENTO DE PESSOAL DE NÍVEL SUPERIOR - CAPES. Avaliação da pós-graduação: relatório de avaliação da trienal 2013 - artes/ música. 2013b. Disponível em: <http://www.capes.gov.br>. Acesso em: 17 mar. 2014. 
CORREIA, Anna Elizabeth Galvão Coutinho; ALVARENGA, Lídia;

GARCIA, Joana Coeli Ribeiro. Publicar é preciso, transformar cientista em máquina não é preciso. DataGramaZero: Revista de Informação, Rio de Janeiro, v. 12, n. 2, jun. 2011.

FOUCAULT, Michel. Vigiar e punir: o nascimento da prisão. Tradução de Raquel Ramalhete. Petrópolis: Vozes, 1987.

HESSEN, Joannes. Teoria do conhecimento. Tradução de João Vergílio Gallerani Cuter. São Paulo: Martins Fontes, 2000.

LUIZ, Ronir Raggio. Avaliação de produtividade acadêmica: uma proposta de quantificação. Revista Brasileira de Pós-Graduação, Brasília, v. 3, n. 6, p. 300-312, dez. 2006.

LUZ, Madel T. Prometeu acorrentado: análise sociológica da categoria produtividade e as condições atuais da vida acadêmica. Physis: Revista de Saúde Coletiva, Rio de Janeiro, v. 15, n. 1, p. 39-57, 2005.

MASSONI, Neusa Teresinha. Epistemologias do século XX. 2005. Dissertação (Mestrado em Ensino de Física) - Universidade Federal do Rio Grande do Sul, Programa de Pós-Graduação em Ensino de Física. Porto Alegre, 2005.

OLIVEIRA, Marcos Barbosa. A avaliação neoliberal na universidade e a responsabilidade social dos pesquisadores. Scientle Studia, São Paulo, v. 6 , n. 3, p. 379-387, 2008.

PONCZEK, Roberto Leon. Deus, ou seja, a natureza: Spinoza e os novos paradigmas da física. Salvador: Edufba, 2009.

PONCZEK, Roberto Leon. Os crocodilos guardiões e a biblioteca da babilônia: manhas, artimanhas e imposturas acadêmicas. Curitiba: CRV, 2013.

ROSA, Alexandre Reis. Nós e os índices: um outro olhar sobre a pressão institucional por publicação. Revista de Administração de Empresas. São Paulo, v. 48, n. 4, out./dez. 2008.

SANTOS, Cássio Miranda. Tradições e contradições da pós-graduação no Brasil. Educação \& Sociedade, Campinas, v. 24, n. 83, p. 627-641, ago. 2003.

\section{Title}

The influence of logical and formal criteria CAPES disciplining of intellectual

Inf. Inf., Londrina, v. 21, n. 1, p. 159 - 184, jan./abr. 2016. 
production in the field of Arts / Music

\begin{abstract}
Introduction: It was discussed how the mediate, logical and formal knowledge of CAPES, represented by its criteria of assessment, has corrobarate for stardardization of intelectual production in the field of arts, in which according to Hessen (2000) it predominates a kind of immediate, informal and intuitive knowledge.

Objective: reflecting the referred question, searching to put in evidence the degree of standardization and systematization of intelectual production in three programs of post-graduate belonging to the field of arts/music, assessed by Capes in 2013.
\end{abstract}

Methodology: It was carried out a comparative analysis between the importance given to artistic production and scientific in the field of arts/music and the effective production of three programs studied, published between 2010 and 2012.

Results: An analyse of datas revealed that even in the field of arts/music, the programs of post-graduate are still more graded, taking into account the quantity of articles published which is the privileged instrument of immediate, intuitive and creative knowledge. Conclusion: the functioning of post-graduate is rooted in a great deal of formal knowledges, expressed in normative documents, through which the CAPES exercises the power, the discipline and stimulus for making intelectual productions standardized.

Keywords: Theory of knowledge. Disciplinary power. Scientific field. Intellectual production. Evaluation system. CAPES.

\title{
Titulo
}

La influencia de la CAPES criterios lógicos y formales disciplinar de la producción intelectual en el campo de las Artes / Música.

\section{Resumen}

Introducción: Se discute cómo el conocimiento mediado, CAPES lógicos y formales, representado por sus criterios de evaluación, ha confirmado a la normalización de la producción intelectual en el campo de las artes, donde como Hesse (2000), prevalece un tipo de conocimiento inmediata, informal e intuitiva.

Objetivo: Para reflejar esa pregunta, hemos tratado de poner de relieve el grado de estandarización y sistematización de la producción intelectual en tres programas de postgrado que pertenece al campo de las Artes / Música, evaluado por la Capes en 2013. Metodología: Con el fin de satisfacer el objetivo formulado, no hubo un análisis comparativo de los pesos asignados a la producción artística y científica en el campo de las Artes / Música y la producción real de los tres programas estudiados, publicada entre los resultados de 2010 y 2012.

Resultados: los resultados revelaron que, incluso en el campo de la arte / música, programas de post-grado son todavía goleadores, teniendo en cuenta el número de artículos científicos publicados, instrumento privilegiado del conocimiento mediada, lógico y formal, en detrimento de las producciones 
Anderson Café; Núbia Moura Ribeiro; Roberto Leon Ponczek

A influência dos critérios lógicos e formais da CAPES na disciplinarização da produção intelectual no campo das artes/música

artísticas, poseen conocimiento inmediato e intuitivo y creativo.

Conclusión: Se concluye que la operación de la Graduate tiene sus raíces en un conjunto de conocimientos formales, expresado en los documentos normativos, a través del cual cabos ejercer el poder, la disciplina y el estímulo para hacer las producciones intelectuales estandarizadas.

Palabras clave: Teoría del conocimiento. El poder disciplinario. Campo científico. La producción intelectual. Sistema de evaluación. CAPES.

Recebido: 20.09.2014

Aceito: 15.03 .2016 